
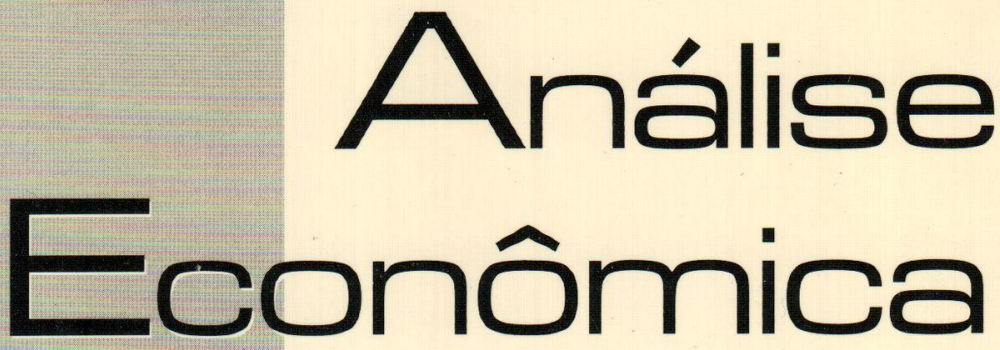

FATOS ESTHLIZADOS E CORRELAÇÁ O NO SETOR BANCÁRIO BRASILEIRO

IGOR AlexandRe C. DE MORAES

Política Monetária, Expectativas e Derivativos: uma ANALISE DO BRASIL PERIODO 1995-98

ROGERIO SOBREIRA

O FEDERAL RESERVE EM DOIS MOMENTOS DISTINTOS: ATUAÇÃO NA GRANDE DEPRESSÃO E NO FINAL DOS ANOS 1990

ROBSON RODRIGUES PEREIRA

BASHLÉIA 2 E ECONOMIAS EMERGENTES: UMA ABORDAGEM MÉDIA-VARIÁNCIA

otaViano Canuto e ANTÓ Nio josé MEIRELLES

VULNERABILIDADES EXTERNAS E INTERNAS DAS ECONOMIAS EMERGENTES E PADRÁ O DE CONTÁ GIO. A EXPERIÉnCIA DA DECADA DE 90

MiLTON PEREIRA OE ASSIS

ENDIVIDAMENTO PÚ BLICO E IMPACTO SOBRE FLUXOS DE CAPITAIS, RISCO-PAIS DIFERENCIAL DE JUROS NO BRASIL (1995-2002): MODELO VAR E TESTES DE CAUSALIDADE FLÁ VIO VILELA VIEIRA

METAS SOCIAIS DE PROCRAMAS DE MICROCRÉ DITO FINANCEIRAMENTE VIÁ VEIS

FERNANDO BATISTA PEREIRA E MARCO CROCCO

Estrutura Produtiva e Performance econó mica das ECONOMIAS ESTAdUAIS BRAsILIRAS NA DECADA DE NOVENTA ADELAR FOCHEZATTO

HISTORIA ECONO MICA Y TEORIA ECONO MICA: ENCUENTROS Y DESENCUENTROS

Gabriel PorciLe

EM BUSCA DA NOÇÃ O EVOLUCIONÁRIA (NEO-

SHUMPETERIANA) DO AUTO-INTERESSE DOS AGENTES: UMA CONTRIBUIÇAO A PARTIR DA LITERATURA SOBRE COOPERAÇÁO INTERFIRMAS

ROBSON ANTONIO GRASS

PRINCiPIOS E APULAÇó Es de REGRESSÁo Local ADALMIR MARQUETTI E LORI VIAL

globalizaçáo, Crescimento e pobreza, a Visäo do BANCO MUNDIAL SOBRE OS EFETTOS DA GLOBALIZAÇÁO NALI DE JESUS DE SOUZA

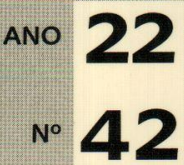




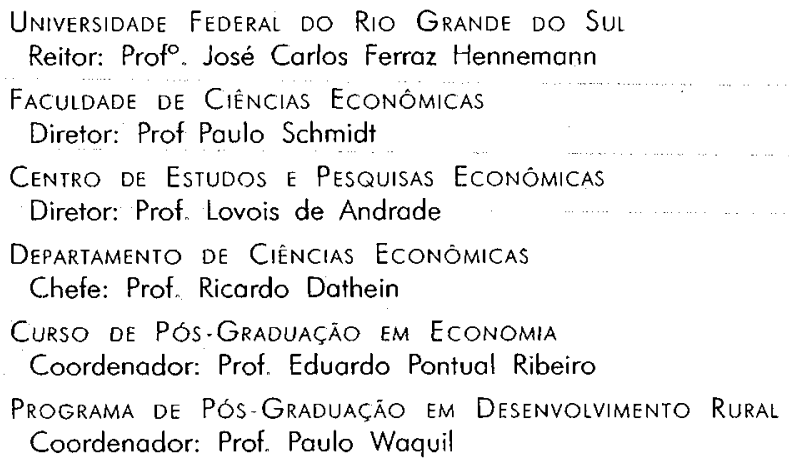

CONSELHO EDITORIAL:

André M. Cunha (UFRGS), Carlos G. A. Mieliz Netto (UFRGS), Carlos H. Hom (UFRGS), Eduardo $A_{n}$ Maldonado Filho (UFRGS), Eduardo P. Ribeiro (UFRGS), Eleutério F. S. Prado (USP), Eugênio Lagemann (UFRGS), Fernando Cardim de Carvalho (UFRJ), Fernando Ferrari Filho (UFRGS), Fernando de Holanda Barbosa (FGV/RJ), Flávio Vasconcellos Comim (UFRGS), Flávio A. Ziegelman (UFRGS), Gentil Corazza (UFRGS), Giácomo Balbinotto Netto (UFRGS), Gilberto de O. Kloeckner(UFRGS), Gustavo Franco (PUC/RJ), Hélio Henkin (UFRGS), Jairo L. Procianoy (UFRGS), Jan A. Kregel (UNCTAD), João Rogério Sanson (UFSC), Joaquim Pinto de Andrade (UnB), Jorge Paulo Araújo (UFRGS), José R. Iglesias (UFRGS), Júlio C. Oliveira (UFRGS), Luis P. Nogueról (UFGS), Luiz E. Faria (UFRGS), Marcelo S. Portugal (UFRGS), Maria Alice Lahorgue (UFRGS), Octávio A. C. Conceição (UFRGS), Orlando Martinelli (UFRGS), Paul Davidson (University of Tennessee), Paulo D. Waquil (UFRGS), Paulo Schmidt (UFRGS), Pedro C. D. Fonseca (UFRGS), Philip Arestis (University of Cambridge), Ricardo Dathein (UFRGS), Roberto C. de Moraes (UFRGS), Ronald Otto Hillbrecht (UFRGS), Sérgio M. M. Monteiro (UFRGS), Sabino da Silvo Porto Jr. (UFRGS), Stefano Florissi (UFRGS) e Werner Baer (University of Illinois at Urbana-Champaign).

COMISSÃO EDITORIAL:

Eduardo Augusto Maldonado Filho, Fernando Ferrari Filho, Gentil Corazza, Marcelo Savino Portugal, Paulo Dabdab Waquil e Roberto Camps Moraes.

EDITOR: Prof. Fernando Ferrari Filho

Egitor Adunto: Prof Gentil Corazza

Secretário: Paulo Roberto Eckent

REVISÁO DE TEXTOS: Vanete Ricacheski

Eottoraçáo Eletrónca: Nucleo de criação e editoraçáo Gráfica UFrgs: leonardo ponso Fundador: Prof. Antônio Carlos Santos Rosa

Os materiais publicados na revista Análise Econômica são da exclusiva responsabilidade dos autores. É permitida a reprodução total ou parcial dos trabalhos, desde que seja citada a fonte. Aceita-se permuta com revistas congêneres. Aceitam-se, também, livros para divulgação, elaboração de resenhas e recensōes Toda correspondência, material para publicação (vide normas na terceira capa), assinaturas e permutas devem ser dirigidos ao seguinte destinatário:

PROF. FERNANDO FERRAR! FILHO

Revista Análise Econômica - Av. João Pessoa, 52 CEP 90040-000 PORTO ALEGRE - RS, BRASIL Telefones: (051) 316-3513 - Fax: (051) 316-3990

Análise Econömíca E-mail: rae@ufrgs.br

Ano 22, $n^{\circ} 42$, morço, 2004 - Porto Alegre

Faculdade de Ciências Econômicas, UFRGS, 2004

Periodicidade semestral, março e setembro.

Tiragem: 500 exemplares

1. Teoria Econômica - Desenvolvimento Regional -

Economia Agrícola - Pesquisa Teórica e Aplicada.

Periódicos. 1. Brasil.

Faculdade de Ciências Econômicas,

Universidade Federal do Rio Grande do Sul. 


\section{Endividamento público e impactos sobre fluxos de capitais, risco-país e diferencial de juros no Brasil (1995-2002): modelo VAR e testes de causalidade}

Flávio Vilela Vieira ${ }^{1}$

Resumo: $O$ trabalho estima um modelo de vetores auto-regressivos (VAR) para a economia brasileira no período de janeiro-1995 a outubro-2002, incluindo risco-país, diferencial de juros, endividamento público e fluxos de capitais (IDE e Portfólio). Os resultados empíricos sugerem que o risco-país e o diferencial de juros respondem por algo em torno de $30 \%$ da variância no endividamento público, embora este não seja relevante para se entender alterações no risco-país, no diferencial de juros e no fluxo de capital. Similarmente, os resultados das análises das funções impulso-resposta revelam que choques no endividamento público não possuem efeitos significativos e duradouros sobre as demais variáveis do modelo. Finalmente, os testes de causalidade indicam causalidade do risco para o endividamento público, e não no sentido inverso, e a não-causalidade em ambos os sentidos para alterações no endividamento público e fluxos de capitais.

Palavras-chave: Fluxos de Capitais, Risco-Brasil, Diferencial de Juros, Endividamento Público; e Modelos VAR.

Abstract: The paper estimates a vector autoregressive (VAR) model for the Brazilian economy during the period of Jan-1995 to Oct-2002, including countryrisk, interest rate differential, public indebtedness (domestic and external), and capital flows (FDI and Portfolio). The empirical results suggest that country-risk and interest rate differential can explain around $30 \%$ of the public debt variance, even though the public indebtedness is not relevant to understand changes all the other three variables of the model (country-risk, interest rate differential and capital flows). Similarly, the impulse-response analysis reveals that shocks in the variable public debt do not have long lasting and significant effects in any of the other variables. Finally, the causality tests suggest the existence of a Granger causality from country-risk to public indebtedness, but not the other way round. Other than this, there is no evidence of causality in both directions for changes indebtedness and capital flows.

Keywords: Capital flows, country-risk, interest rate differential, public indebtedness, vector autoregressive models (VAR).

Classificação JEL: F41, C22, H63.

' Professor do Instituto de Economia da Universidade Federal de Uberlândia. PhD em Economia pela University of New Hampshire, EUA. Pesquisador do CNPq. E-mail: flaviovieira@ufu.br 


\section{Introdução}

O presente artigo visa desenvolver uma análise empírica tendo por base duas questōes fundamentais para a economia brasileira a partir de meados dos anos 1990. A primeira delas diz respeito ao papel que o risco-país e o diferencial de juros exercem sobre o grau de endividamento público (interno e externo). A segunda questão refere-se ao papel que o grau de endividamento público exerce sobre as variáveis fluxo de capitais, risco-país e diferencial de juros.

A análise de tais questões envolverá inicialmente uma breve revisão da literatura sobre fluxos de capitais em países emergentes com uma atenção mais detalhada para o caso latino-americano, no intuito de estabelecer quais são as variáveis a serem examinadas na parte empírica do trabalho aqui proposto, além de assimilar algumas lições teóricas sugeridas pela literatura que podem, ou não, serem corroboradas empiricamente para o caso brasileiro para o período de janeiro de 1995 a outubro de 2002.

O desenvolvimento da parte empírica será feito a partir da estimação de um modelo de vetores auto-regressivo (VAR), onde as variáveis do mesmo são risco-país, diferencial de juros, endividamento público e fluxos de capitais (IDE e Portfólio). A metodologia VAR justifica-se ao permitir o entendimento da interação dinâmica entre as variáveis sem ter que assumir a priori endogenidade de uma ou mais variáveis como é feita na análise econométrica tradicional. Além disso, o instrumental de análise subjacente aos modelos VAR permite analisar empiricamente qual a participação de cada uma das variáveis do modelo no entendimento das alteraçōes em uma das variáveis (análise de decomposição de variância) ou mesmo a resposta de uma das variáveis face à ocorrência de um choque em uma das variáveis do modelo (análise das funções impulso-resposta). Resta ressaltar que, além dos dois testes sugeridos acima, será realizado também o teste de causalidade entre grau de endividamento público e risco país.

$\mathrm{O}$ artigo está dividido em cinco seções. A segunda desenvolve uma breve revisão da literatura sobre fluxos de capitais $e$ o papel dos diferenciais de juros e endividamento público em situações de mudanças nos fluxos internacionais de capitais. A seção três tem um cunho metodológico onde é apresentado o 
modelo VAR além da descrição das variáveis. A seção quatro sistematiza os resultados e análises empíricas, e a seção cinco apresenta as considerações finais.

\section{Fluxos de capitais: uma breve revisão da literatura e o caso brasileiro}

A presente seção do trabalho visa sistematizar as principais conclusões sugeridas pela literatura sobre o papel dos fluxos de capitais ao longo dos anos 1990 na América Latina, e no Brasil em especial, com destaque para questões como o papel dos fluxos de capitais no processo de ajuste das contas externas em períodos onde há uma alternância na ocorrência de crises financeiras internacionais (segunda metade dos anos 1990) e no próprio processo de liberalização financeira e comercial adotado pelos diversos países em desenvolvimento. Além disso, abordou-se alguns argumentos relacionados ao papel exercido pelo risco-país e o diferencial de juros em termos de afetar os fluxos de capitais, além da questão do déficit fiscal que é vista como crucial não apenas por estar relacionada à política de esterilização freqüentemente adotada em vários países latino-americanos, mas também em função de estar diretamente relacionada com as reformas estruturais implementadas (em maior ou menor grau) nos mais diversos países.

A motivação inicial para a elaboração do presente trabalho de pesquisa tem relação com a pesquisa desenvolvida recentemente por Razin e Sadka (2002) por se constituir em uma das análises sobre a economia brasileira que incorpora a questão da relação entre as variáveis risco-país e o medo da moratória, e como tal situação pode afetar os fluxos de capitais além de elevar o diferencial de juros e o próprio custo do serviço da dívida pública. Uma das questóes tratadas pelos autores diz respeito aos fundamentos macroeconômicos brasileiros que são vistos como sendo consistentes durante o primeiro semestre de 2002. O modelo desenvolvido pelos autores trabalha com a idéia de que o riscopaís depende positivamente dos investimentos agregados que são exógenos aos governos e às empresas, e negativamente do total do déficit fiscal (incluindo o pagamento de juros). Os autores ressaltam ainda que no caso de dívida pública de curto prazo, há uma indexação do serviço da dívida ao prêmio de risco do país. Uma 
das conclusões de Razin e Sadka (2002) é a de que uma correção externa da avaliação de crédito do país pode exercer efeitos domésticos em termos de redução na taxa de juros, restaurar os investimentos e reduzir o déficit fiscal. ${ }^{2}$

Um dos trabalhos pioneiros a estudar a questão dos fluxos de capitais na América Latina no início dos anos 1990 foi o de Calvo et al. (1993), em que os autores defendem o argumento de que os fatores cíclicos externos são os principais determinantes dos fluxos de capitais para a América Latina, e que as reformas de mercado implementadas a partir de então têm exercido um papel importante na atração destes fluxos de capitais externos, tanto sob a forma de investimento direto estrangeiro (IDE) como de investimentos em carteira. Uma das preocupaçōes centrais da análise de Calvo et al. (1993) é de examinar a relação entre os fluxos de capitais e o comportamento da taxa de câmbio real dado que um excesso de entrada de capitais em geral está associado a uma apreciação cambial real com conseqüentes problemas no desempenho das contas externas.

Edwards (1998) elabora uma análise histórica e empírica sobre a entrada e saída de capitais da América Latina desde os anos 1980 até final dos anos 1990, sendo que uma das constatações fundamentais do autor está relacionada à alta volatilidade dos fluxos de capitais e ao problema da vulnerabilidade externa das diversas economias latino-americanas. A ocorrência de crises financeiras internacionais tem tido um alto grau de contágio entre os diversos países da região quando comparado ao caso asiático, o que pode ser em parte entendido pela diferença dos graus de mobilidade de capitais entre os dois continentes e pela maneira com que cada país e região têm administrado os controles sobre os fluxos de capitais, além do grau de endividamento externo latino-americano que é bem maior do que o caso asiático e do aspecto tardio de implementação das reformas orientadas para o mercado (liberalização comercial e financeira, e privatização). A história

${ }^{2}$ Feitas as considerações acima sobre o trabalho de Razin e Sadka (2002), percebe-se que o arcabouço empírico desenvolvido pelos autores baseia-se em variáveis que serão aqui analisadas, ou seja, o VAR a ser estimado envolve as variáveis fluxo de capital, risco-país, diferencial de juros e endividamento público. O objetivo empírico do presente trabalho, no entanto, não está focado na questão do custo financeiro envolvido com o pagamento dos juros pelo setor público, mas sim na possibilidade de que o grau de endividamento público possa ter uma relação com o risco-país e com os fluxos de capitais, embora a própria utilização da variável diferencial de juros capta de alguma forma tal custo. 
recente da América Latina tem mostrado que o continente atravessou momentos de crise de endividamento externo (início anos 1980), a implementação do Plano Brady (final dos anos 1980) e o relativo equacionamento do problema da divida externa de vários países latino-americanos, o início de um período de atração de capitais externos a partir dos anos $1990 \mathrm{com}$ as reformas estruturais implementadas nos mais diversos países, e as crises que se sucederam a partir de 1994 com o episódio mexicano. ${ }^{3}$

O trabalho de Calvo (1997) sobre fluxos de capitais e os episódios de crise vivenciados pelo México e pela Tailândia revela um papel importante das autoridades monetárias em na provisão de empréstimos do banco central para o setor financeiro, fato este que implica uma expansão do crédito doméstico e uma perda de reservas, resultado oposto ao previsto pelo modelo de ataque especulativo e crise do balanço de pagamentos de Krugman (1979).

Langhammer and Wobmann (2000) ressaltam que os fluxos de capitais externos têm um papel importante para os países emergentes em termos de prover recursos adicionais para investimentos e de reduzir as limitações em termos de disponibilidade de divisas (moeda estrangeira), porém tais fluxos geralmente estão associados a problemas macroeconômicos em períodos de crise que sucedem os períodos de expansão econômica inicial.

Gourinchas et al. (2001) trata a questão dos booms de empréstimos e sua relação com as crises financeiras, sendo que os resultados empíricos apontam para o fato de que os booms de empréstimos em geral estão associados a seis elementos centrais (aumento no investimento doméstico, aumento das taxas de juros, diminuição das reservas internacionais, deterioração da conta corrente, apreciação real do câmbio, diminuição da taxa de crescimento econômico), além da constatação de que a América Latina fica mais volátil e vulnerável a crises financeiras e do balanço de pagamentos.

A relação entre fluxos de capitais e diferencial de juros foi analisada, dentre outros, por Larrain et al. (1997), sendo que tal diferencial de juros tem se mostrado importante para explicar os fluxos de capitais de curto prazo, porém o mesmo não acontece no longo prazo. Ainda assim, os movimentos nas taxas de juros internacionais acabam exercendo influência enquanto sinalizador

3 Ver Taylor (1999) para uma análise histórica sobre fluxos de capitais na América Latina desde o início do sécúlo XX, destacando as limitaçōes de poupança doméstica e o papel dos capitais externos na melhora dos níveis de renda per capita da região. 
para os fluxos de capitais se moverem para regiões que oferecem um maior diferencial de juros, como tem sido o caso da América Latina ao longo das últimas décadas.

O trabalho de Garcia e Valpassos (1998) sobre os fluxos e controles de capitais na economia brasileira ressalta a ineficácia dos controles de capitais em prevenir a entrada de capitais de curto prazo especulativos que, em geral, eram investidos em títulos da dívida pública, mas tiveram um efeito temporário. $O$ diferencial de juros, segundo os autores, tem sido o principal determinante dos fluxos de capital pra o Brasil desde o início dos anos 1990, e a composição dos fluxos de capital tem-se deslocado dos fluxos de curto prazo em carteira para os investimentos direto estrangeiros no transcorrer da década passada e em especial a partir do período de estabilidade inflacionária. Os autores ressaltam ainda que os fluxos de capitais exerceram um papel importante em termos da deterioração das contas internas expressa pelo aumento da dívida pública brasileira. O cenário brasileiro dos anos 1990 e a implementação do Plano Real têm como uma de suas características fundamentais o acúmulo aumento do nível de reservas internacionais e uma melhoria na conta de capital, sendo que tais elementos aliados a uma política de rigidez cambial a partir de 1994 têm como uma de suas conseqüências a recorrente adoção de políticas de esterilização (lançamento de títulos da dívida pública) como forma de evitar uma excessiva expansão monetária com temores inflacionários atrelados a tal expansão. O problema é que esta política de esterilização estava atrelada à manutenção de altas taxas de juros no mercado doméstico, comprometendo assim o próprio ajuste fiscal brasileiro.

Um dos estudos sobre o papel da paridade descoberta da taxa de juros, aplicado para 23 países durante o período de crise dos anos 1990, é o de Flood and Rose (2001) que revela que a paridade descoberta dos juros funciona melhor para países que atravessaram períodos de crise quando comparados aos países que não enfrentaram tal situação independentemente de serem ricos ou pobres e do regime cambial adotado. ${ }^{4} \mathrm{~A}$ idéia subjacente à paridade descoberta de juros é de que o diferencial de juros deve ser em média igual à mudança na taxa de câmbio ex-post, e, sendo assim, países com maiores diferenciais de juros devem

${ }^{4}$ Brasil, México e Argentina estão incluídos dentre os países analisados. 
sofrer uma depreciação cambial, mas os resultados empíricos não têm demonstrado tal comportamento. Durante períodos de crise, há uma tendência para que a paridade descoberta tenha uma maior relevância em função da maior volatilidade do câmbio e dos juros.

Uma das conclusões apontadas pela literatura sobre os fluxos de capitais em países emergentes sujeitos aos efeitos negativos de crises financeiras (liquidez) internacionais requer a adoção de uma maior flexibilidade cambial em conjunto com um melhor sistema de supervisão bancária e a implementação de reformas estruturais (lado fiscal), sem que, com isso, possa se imaginar que tais países estariam imunes a choques financeiros internacionais dentro de um contexto internacional marcado por uma crescente globalização financeira.

\section{Modelagem, variáveis e testes econométricos}

A análise empírica baseia-se em séries temporais mensais para a economia brasileira no período de janeiro de 1995 a outubro de 2002. Durante tal período, a evolução macroeconômica brasileira tem tido uma relação bastante estreita com o comportamento de variáveis como os fluxos de capitais, que, por sua vez, têm uma forte relação com variáveis como o risco-país, o diferencial de juros doméstico em relação aos juros internacionais, e a política de endividamento público doméstico e externo.

Os dados e as variáveis utilizados na estimação do modelo VAR para o período de janeiro de 1995 a outubro de 2002 são as seguintes:

EndPub = Endividamento Público = Dívida líquida total do setor público (\% do PIB) mais a dívida externa líquida do setor público (\% PIB).

UIP $=$ diferencial de juros representado pela paridade descoberta da taxa de juros. ${ }^{5}$

Risco-País = Média mensal do J. P. Morgan Emerging

5. O cálculo da variável UIP foi feita utilizando-se da seguinte fórmula:

$$
U I P=\left[\frac{(1+i)}{(1+e) x\left(1+i^{*}\right)}-1\right] * 100
$$

onde se utilizou a taxa Selic como proxy para os juros domésticos (i), a Prime Rate para os juros externos $\left(i^{*}\right)$, e a taxa de variação do câmbio nominal (e). 
Market Bond Index $(E M B I+)$ em pontos base.

FK = fluxo de capital (somatório de IDE e Portfólio) em Milhões de US\$.

O primeiro passo a ser adotado na parte empírica envolve o teste de Augmented Dickey- Fuller (ADF) para se detectar a estacionaridade ou não das séries temporais. $\mathrm{O}$ teste $\mathrm{ADF}$ envolve a regressão da primeira diferença de uma determinada variável contra uma constante, uma tendência temporal, a variável em nível defasada, e o somatório das defasagens das primeiras diferenças das variáveis, e o resultado envolve a análise do chamado t-ADF e sua significância. A expressão para o teste de $\mathrm{ADF}$ para uma variável $Y$ qualquer é representada pela seguinte equação:

$$
\Delta Y_{t}=\mu+\gamma t+\delta Y_{t-1}+\Sigma_{i=1}^{n} \beta_{i} \Delta Y_{t i}+\varepsilon_{t}
$$

onde $\mathrm{t}$ indica a tendência temporal, $\mathrm{n}$ o número de defasagens, $\Delta$ é o operador de primeira diferença, e $\varepsilon_{t}$ o termo de erro.

A hipótese nula do teste é a da existência de raízes unitárias, o que indica a não-estacionaridade da série caso não se rejeite tal hipótese nula, e a estacionaridade das séries quando tal hipótese nula é rejeitada. ${ }^{\circ} \mathrm{A}$ idéia básica é de se fazer o teste $\mathrm{ADF}$ para todas as variáveis em nível, e para os casos onde não se pode rejeitar a hipótese nula de raízes unitárias; a segunda etapa visa implementar o mesmo teste ADF para tais séries em primeira diferença no intuito de analisar se a hipótese nula pode ser então rejeitada, o que indicaria que estas séries são não-estacionárias em nível, mas estacionárias em primeira diferença.?

A estimação dos modelos VARs será feita para um sistema de quatro variáveis incluindo risco-país, diferencial de juros, endividamento público e fluxo de capital no intuito de se utilizar as análises de decomposição de variância e funções impulsoresposta para responder às duas questões inicialmente propostas, ou seja, sobre o papel do diferencial de juros e do risco-país sobre o endividamento público, e deste sobre os fluxos de capitais. A utilização do modelo VAR é justificada em função não

\footnotetext{
- Os testes ADF foram implementados iniciando-se com $n+1$ defasagens, onde $n$ é a frequência dos dados (mensal), portanto iniciou-se com 13 defasagens, reduzindo-se uma a uma caso a defasagem utilizada não se mostrasse significativa sobre o ponto de vista estatistico. Utilizou-se o software Eviews 3.0 para os testes de ADF, assim como para o VAR e as respectivas análise de decomposição de variância e das funções impulso-resposta.

${ }^{7}$ Os gráficos em nível e primeira diferença para as variáveis UIP, Risco e EndPub, e apenas em nivel para o caso de FK encontram-se no apêndice deste trabalho.
} 
apenas da necessidade de se analisar o impacto dinâmico de distúrbios aleatórios no sistema de variáveis, sem a preocupação convencional de se estabelecer a priori quais as variáveis endógenas e exógenas do modelo, mesmo porque não se pretende aqui construir um modelo sobre fluxo de capital, ou riscopaís, ou diferencial de juros, ou mesmo sobre endividamento público, mas uma análise que forneça subsídios para o entendimento da interação entre as mesmas no tempo. Neste sentido, a modelagem VAR fornece dois instrumentos adequados aos nossos objetivos tendo por base as duas perguntas iniciais feitas na introdução deste trabalho, que são a análise de decomposição de variância e as funções impulso-resposta.

$O$ instrumental analítico das funções impulso-resposta capta o efeito no tempo de um choque de um desvio-padrão a uma mudança nos valores correntes e futuros das variáveis endógenas do VAR. Por outro lado, a análise de decomposição de variância fornece uma metodologia distinta para se analisar a dinâmica do sistema no tempo, sendo que a idéia é fornecer informação sobre a importância relativa de choques aleatórios em cada uma das variáveis do sistema sobre as demais variáveis.

O teste de causalidade de Granger (1969) visa examinar a questão da causalidade entre risco-país e endividamento público num primeiro momento, e, em segundo lugar, um teste de causalidade entre grau de endividamento público e fluxos de capitais no intuito de se investigar a hipótese de que os investidores externos e as próprias agências de risco atribuem importância para o grau de endividamento público ao avaliarem a possibilidade de investir em um determinado país. ${ }^{8} \mathrm{~A}$ idéia do teste de causalidade de Granger ao testar se uma determinada variável $\mathrm{x}$ causa y, é saber quanto se pode explicar dos valores correntes de y tendo por base os valores passados de y, e se tal explicação pode ser melhorada ao incluir valores defasados da variável x. A hipótese nula do teste é de que a variável $\mathrm{x}$ não causa y no sentido Granger, sendo assim, a rejeição da hipótese nula indica causalidade entre as variáveis.

${ }^{8}$ Os procedimentos econométricos, tanto para a análise de decomposição de variância como para as funções impulso-resposta e o teste de causalidade de Granger, foram feitos utilizando-se o software E-Views 3.0. 


\section{Análise dos resultados empíricos}

A análise dos resultados econométricos será apresentada em cinco subseções. A primeira diz respeito aos testes de raízes unitárias para detectar a estacionaridade das séries temporais; a segunda contém os resultados referentes à seleção das defasagens dos dois modelos VAR incluindo os critérios de Akaike e Schwarz; a terceira diz respeito à análise da decomposição de variância; a quarta contém as funçōes impulso-resposta; ${ }^{9}$ e, por fim, o teste de causalidade de Granger para as variáveis risco-país e endividamento público.

\subsection{Testes de raízes unitárias}

Os resultados da tabela 1 sistematizam os testes de raízes unitárias revelando que as séries de risco, diferencial de juros (UIP) e endividamento público são não-estacionárias em nível, mas estacionárias em primeira diferença. Já a série fluxos de capitais (FK) é estacionária em nivel. ${ }^{10}$ Assim sendo, a estimação dos dois VARs será feita contendo apenas variáveis estacionarias para a análise de decomposição de variância e o teste de causalidade que exigem estacionaridade das séries a serem analisadas. No caso das funções impulso-resposta, a análise envolve choques nas variáveis em nível e não em primeira diferença.

\subsection{Seleção dos modelos de vetores auto-regressivos}

A seleção do modelo VAR para risco-país, diferencial de juros, endividamento público e fluxos de capitais teve por base

\footnotetext{
9 Ver Holland e Vieira (2003) para uma análise econométrica similar à adotada neste trabalho, porém para um modelo que inclui fluxos de capitais, risco-país, diferencial de juros e controles de capitais, porém sem analisar o papel da variável endividamento público. Além disso, os autores elaboraram uma análise que não apenas analisava os fluxos de capitais totais (FK) como no presente trabalho, mas também dois outros VARs onde se segmentava os fluxos totais em seus dois principais componentes (IDE e Portfólio).

${ }^{10}$ A variável diferencial de juros (UIP) em nivel e com duas defasagens indicou estacionariedade, porém apenas a $10 \%$, enquanto a análise dos correlogramas sugere a não-estacionariedade em nível. Assim sendo, optou-se por trabalhar com a série em primeira diferença onde a estacionariedade foi verificada independentemente do número de defasagens utilizada no teste de ADF. Os valores críticos para rejeiçāo da hipótese nula da existência de raízes unitárias foram obtidos a partir de MacKinnon (1991) e gerados pelo software Eviews 3.0.
} 
Tabela 1: Teste de raízes unitárias (ADF) Brasil jan/1995 a out/2002

\begin{tabular}{ccc}
\hline Variáveis & t-ADF * & Número de Defasagens \\
\hline UIP & $-3,238350^{\star}$ & 2 \\
\hline Risco & $-1,671556$ & 1 \\
\hline EndPub & $-2,279431$ & 0 \\
\hline FK & $-5,459235^{\star * *}$ & 1 \\
\hline$\Delta$ UIP & $-10,58199^{* \star *}$ & 1 \\
\hline$\Delta$ Risco & $-7,465701^{\star * *}$ & 1 \\
\hline$\Delta$ EndPub & $-6,665705^{* \star *}$ & 1 \\
\hline
\end{tabular}

* ${ }^{* *} e^{* \star *}$ indicam significância aos níveis de 10,5 e $1 \%$, respectivamente $\Delta$ indica primeira diferença

* Incluindo constante e tendência temporal

um processo de redução do número de defasagens de cada modelo tomando por base os resultados dos critérios de Akaike e Schwarz. Iniciou-se a estimativa do VAR com quatro defasagens, e reduziu-se tal número até uma defasagem, computando-se os dois critérios de seleção acima mencionados.

A tabela 2 abaixo se refere aos resultados da seleção do modelo para um VAR com quatro variáveis. Os resultados indicam que o modelo com uma defasagem deve ser o escolhido por apresentar um menor valor para os critérios de Akaike e Schwarz. A escolha dos modelos VAR e de sua defasagens serve inclusive de referencial na obtenção dos resultados para a análise de decomposição de variância na seqüência.

Tabela 2: Seleção do modelo para o VAR (FK, DRisco, DUIP e DEndPub)

\begin{tabular}{cccc}
\hline Sistema / Método & Log Likelihood & Akaike (AIC) & Schwarz (SC) \\
\hline Sistema com 4 defasagens & $-1775,357$ & $-1773,829$ & $-1771,928$ \\
\hline Sistema com 3 defasagens & $-1799,679$ & $-1798,523$ & $-1797,079$ \\
\hline Sistema com 2 defasagens & $-1835,661$ & $-1834,870$ & $-1833,876$ \\
\hline Sistema com 1 defasagem & $-1892,410$ & $-1891,975$ & $-1891,427$ \\
\hline
\end{tabular}

Dados de jan.-95 a out.-02

$D=$ primeira diferença

Endividamento público e impacto sobre fluxo de capitais, risco-país... 


\subsection{Análise de decomposição de variância}

A tabela 3 sistematiza os resultados para a análise de decomposição de variância para o modelo VAR com quatro variáveis (fluxo de capital, risco-país, diferencial de juros e endividamento público), sendo que os principais resultados apontam para a insignificância da variável endividamento público na explicação da variância das demais variáveis. Além disso, percebe-se que diferencial de juros e risco-país explicam, conjuntamente, menos do que $7 \%$ da

Tabela 3: Decomposição de variância do modelo utilizando o fluxo de capital, risco, diferencial de juros e endividamento público

\begin{tabular}{|c|c|c|c|c|c|}
\hline \multicolumn{6}{|c|}{ Decomposição de variância do FK } \\
\hline Período (meses) & S.E & FK & DUIP & DRISCO & DENDPUB \\
\hline 1 & 1905,458 & 100,0000 & 0,000000 & 0,000000 & 0,000000 \\
\hline 2 & 2093,998 & 93,90933 & 3,836743 & 1,448870 & 0,805058 \\
\hline 3 & 2117,695 & 92,38734 & 4,749465 & 2,074460 & 0,788737 \\
\hline 4 & 2119,603 & 92,22231 & 4,902717 & 2,086027 & 0,788941 \\
\hline 5 & 2119,781 & 92,22171 & 4,903249 & 2,085678 & 0,789358 \\
\hline \multicolumn{6}{|c|}{ Decomposição de Variância do DUIP } \\
\hline 1 & 6,858804 & 0,192759 & 99,80724 & 0,000000 & 0,000000 \\
\hline 2 & 7,101984 & 6,289411 & 93,39334 & 0,312293 & 0,004960 \\
\hline 3 & 7,161252 & 7,213780 & 92,25975 & 0,469121 & 0,057352 \\
\hline 4 & 7,168548 & 7,244406 & 92,17537 & 0,522991 & 0,057235 \\
\hline 5 & 7,169094 & 7,243673 & 92,17472 & 0,524327 & 0,057280 \\
\hline \multicolumn{6}{|c|}{ Decornposição de Variância de DRISCO } \\
\hline 1 & 132,7643 & 16,77940 & 0,408143 & 82,81245 & 0,000000 \\
\hline 2 & 141,0617 & 15,66027 & 8,515805 & 75,80161 & 0,022306 \\
\hline 3 & 141,6213 & 15,82214 & 8,943716 & 75,20959 & 0,024557 \\
\hline 4 & 141,7377 & 15,94305 & 8,933655 & 75,09363 & 0,029667 \\
\hline 5 & 141,7616 & 15,95412 & 8,940521 & 75,07563 & 0,029732 \\
\hline \multicolumn{6}{|c|}{$\begin{array}{c}\text { Decomposição de Variância } \\
\text { de DENDPUB }\end{array}$} \\
\hline 1 & 2,217142 & 7,348844 & 19,19073 & 2,797230 & 70,66320 \\
\hline 2 & 2,436315 & 6,759319 & 16,04122 & 12,92568 & 64,27378 \\
\hline 3 & 2,461815 & 6,693333 & 17,05399 & 12,84755 & 63,40513 \\
\hline 4 & 2,464006 & 6,772879 & 17,05091 & 12,83450 & 63,34171 \\
\hline 5 & 2,464293 & 6,781473 & 17,04784 & 12,84226 & 63,32842 \\
\hline
\end{tabular}


variância nos fluxos de capitais, enquanto que os fluxos de capitais possuem um maior poder explicativo para o diferencial de juros $(7,2 \%)$ e para o risco-país $(15,9 \%)$.

Os fluxos de capitais têm importância significativa nas mudanças do risco-país, fato, este, indicativo de que as avaliações sobre o grau de solvência da economia são em parte explicadas pelo próprio volume de entrada ou saída de capitais externos, tanto sob a forma de IDE como de investimento em carteira. As duas principais variáveis explicativas das alterações no grau de endividamento público (externo e interno) são o diferencial de juros $(17 \%)$ e o risco-país (13\%), porém o fluxo de capital também tem um papel relevante $(6,7 \%)$ sobre o comportamento do grau de endividamento público. Em conjunto, as três variáveis (fluxo de capital, risco-país e diferencial de juros) são responsáveis por mais de $37 \%$ da variância no endividamento público. O papel relevante do diferencial de juros e do risco-país para o grau de endividamento público é algo esperado, e soma-se a este resultado a influência que os fluxos de capitais exercem sobre o endividamento público dado que parte destes fluxos é canalizada para a compra de títulos públicos internos e externos, afetando assim o grau de endividamento público.

\subsection{Análise das funções impulso-resposta}

A análise dos gráficos de impulso-resposta revela que o fluxo de capital não é influenciado pelo grau de endividamento do setor público, sendo afetado apenas no curto prazo e em uma magnitude limitada pelo diferencial de juros (positivamente) e pelo risco-Brasil (negativamente). Quanto ao diferencial de juros, pode-se argumentar que o mesmo sofre impacto negativo quanto à ocorrência de choques nos fluxos de capitais ao longo dos três primeiros meses, um impacto positivo suave do risco-Brasil nos cinco primeiros meses, e um pequeno impacto negativo do grau de endividamento público nos três meses iniciais após a ocorrência dos choques.

O risco-país sofre uma pequena variação inicial negativa em relação a mudanças nos fluxos de capitais e diferencial de juros, porém se mostrou insensível com relação a alterações no grau de 
endividamento público. Finalmente, o grau de endividamento público quase não se altera na ocorrência de choques nos fluxos de capitais, sofrendo um suave e pequeno impacto negativo (positivo) em função de alterações no diferencial de juros (risco-país).

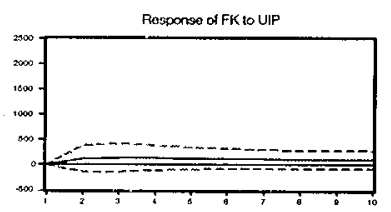

Responso of UIP to FK

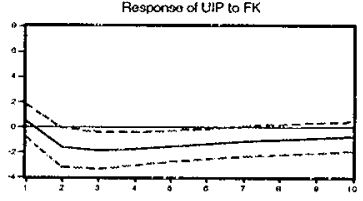

Responso of RisCO to FK

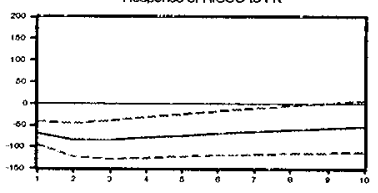

Resconso of ENDPUB to FK

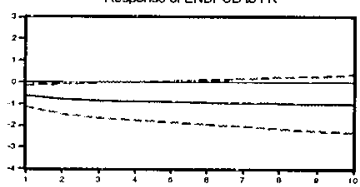

Responso of FK to RisCO

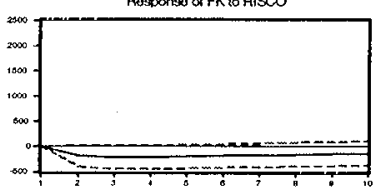

Response of UiP b RISCO

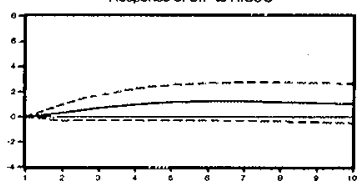

Feesponse of RISCO to UIP

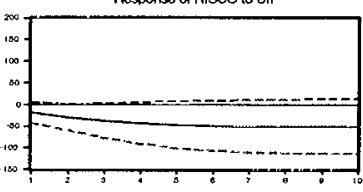

Rosponse of ENDPUB to U:P

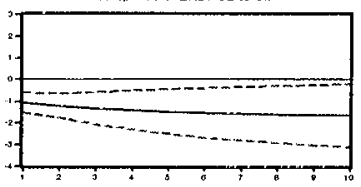

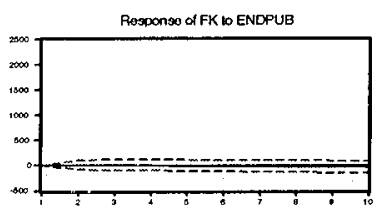

Fesponse of UIP to ENDPUB

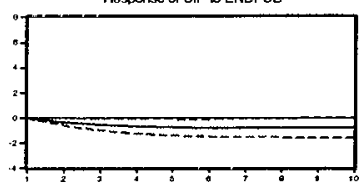

Response of AISCO to ENDPUB

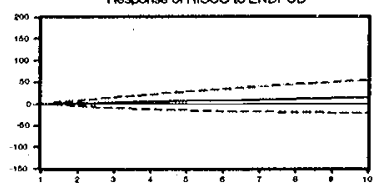

Posconso of ENDPUB to RISDOO

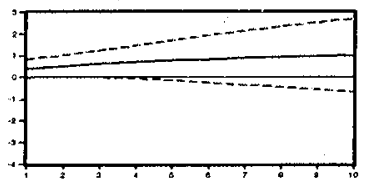

\section{Gráficos das funções Impulso-resposta Response to One S.D. Innovations \pm 2 S.E.}

4.5 Causalidade entre Risco-Brasil, endividamento público e fluxo de capitais

Os resultados da tabela 4 abaixo referente ao teste de causalidade de Granger para as variáveis risco-país e endividamento público revelam que não podemos rejeitar a hipótese nula de não-causalidade entre alterações no grau de endividamento público e mudanças no Risco-Brasil, porém o inverso não é verdadeiro, e as alterações no Risco-Brasil têm uma causalidade no sentido Granger sobre o grau de endividamento público. ${ }^{11}$ Este resultado do teste de causalidade vem, de certa maneira, ainda que com

${ }^{11}$ Os resultados independem do número de defasagens utilizadas. 
objetivos e interpretações distintas que o distingue da análise de decomposição de variância, corroborar os resultados desta, onde o endividamento público não se mostrou significativo para entender as demais variáveis do modelo (incluindo o risco-país), porém o risco-país tem relativa importância para se entender a variância do endividamento público através do efeito que o risco-país exerce sobre a avaliação externa da economia brasileira, e, em última instância, a disponibilidade de recursos a serem direcionados para a compra de títulos públicos internos e externos.

O caso do teste de causalidade de Granger para mudanças no endividamento público e fluxo de capital revela que não podemos rejeitar a hipótese nula de não-causalidade entre fluxos de capitais e mudanças no grau de endividamento público (para 1 ou 2 defasagens), porém, no caso de alterações no grau de endividamento público e fluxos de capitais, a hipótese nula (não-causalidade) é rejeitada apenas com uma defasagem e a $5 \%$ de significância. Assim sendo, pode-se argumentar que há indícios de que existe alguma influência, ainda que relativamente frágil, das mudanças no grau de endividamento público sobre os fluxos de capitais, porém tal resultado não se sustenta quando da adição de defasagens adicionais.

Baseado na análise de decomposição de variância e nas funções de impulso resposta e mesmo na rejeição da hipótese nula apenas com uma defasagem e a $5 \%$, as evidências apontam para a não-causalidade entre endividamento público e fluxos de capitais.

Tabela 4: Teste de causalidade entre Risco-Brasil, endividamento público e fluxo de capitais

\begin{tabular}{ccccc}
\hline $\begin{array}{c}\text { Hipótese Nula } \\
\text { (não causalidade) }\end{array}$ & Estatística-F & Probabilidade & Estatística-F & Probabilidade \\
\hline Número de Defasagens & $\mathbf{1}$ & & $\mathbf{2}$ & \\
\hline $\begin{array}{c}\text { DEndPub não causa } \\
\text { (Granger) DRisco }\end{array}$ & 0,84593 & 0,36019 & 0,91706 & 0,40356 \\
\hline $\begin{array}{c}\text { DRisco não causa } \\
\text { (Granger) DEndPub }\end{array}$ & $\mathbf{1 6 , 2 9 0 7 ^ { * * }}$ & 0,00011 & $7,915433^{* *}$ & 0,00070 \\
\hline $\begin{array}{c}\text { DEndPub não causa } \\
\text { (Granger) FK }\end{array}$ & $3,97575^{*}$ & 0,04922 & 2,26633 & 0,10985 \\
\hline $\begin{array}{c}\text { FK não causa } \\
\text { (Granger) DEndPub }\end{array}$ & 1,15143 & 0,28615 & 0,59221 & 0,55534 \\
\hline
\end{tabular}

* $e^{* *}$ indicam rejeição da hipótese nula (não-causalidade) a $5 \%$ e $1 \%$, respectivamente Período: jan/1995 a out/2002 


\section{Considerações finais}

O objetivo básico da análise econométrica desenvolvida neste trabalho visa analisar a interação dinâmica entre as variáveis fluxo de capitais, risco-país, diferencial de juros e endividamento público para a economia brasileira no período de janeiro de 1995 a outubro de 2002. Uma das novidades em relação a análises anteriores sobre fluxos de capitais deve-se ao fato da inclusão da variável grau de endividamento público, embora não tenha havido a preocupação de incluir a questão dos controles de capitais, dado que a mesma já foi suficientemente explorada pela literatura para o caso brasileiro durante a última década.

A utilização de dois modelos de vetores auto-regressivos (VAR) e os instrumentais analíticos vinculados a este tipo de investigação econométrica para séries temporais revelam alguns aspectos interessantes. Os resultados empíricos sugerem que o riscopaís e o diferencial de juros respondem por cerca de $30 \%$ da variância no endividamento público, embora endividamento público não seja relevante para o entendimento da variância nas demais variáveis (risco-país, diferencial de juros e fluxo de capital) dos modelos. A análise de impulso-resposta revela que choques no endividamento público não possuem efeitos significativos e duradouros sobre as demais variáveis do modelo, enquanto os resultados do teste de causalidade de Granger indicam causalidade do risco-país para o endividamento público, mas não no sentido inverso, e não-causalidade entre endividamento público e fluxos de capitais.

A síntese dos resultados empíricos pode ser expressa através da constatação de que o grau de endividamento público (interno e externo) como percentual do PIB não é uma variável (informação) relevante ao entendimento de mudanças nos fluxos de capitais, no diferencial de juros, e nem mesmo sobre o risco-país para a economia brasileira no período de 1995 a 2002. Apesar do resultado acima, deve-se ter claro que o diferencial de juros e o risco-país devem, de alguma forma, captar os fundamentos da avaliação externa sobre a economia brasileira, e, neste sentido, é de se esperar que a significância, de uma variável como o grau de endividamento externo, seja minimizada ou mesmo redunde em insignificância sob o ponto de vista econométrico. 


\section{Referências bibliográficas}

CALVO, G. (1997) Capital Flows: Emerging Issues Bogotá, Outubro, 1997. Mimeo.

CALVO, G.; L. LEIDERMAN, L. e REINHART, C. M. (1993) Capital inflows and real exchange rate appreciation in Latin America. IMF Staff Papers. Vol. 40(1). Março, 1993.

CARDOSO, E. e GOLDFAJN, I. (1998). Capital flows to Brazil: the endogeneity of the capital controls. IMF Working Paper 115. Washington, D.C: IMF, September, 1998.

DE GGREGORIO, J., EDWARDS, S. e VALDES, R. O. (2000). Controls on capital inflows: do they work? NBER Working Paper Series 7645. Cambridge, USA, Abril, 2000.

EDISON, H. e REINHART, C. (2000). Stopping Hot Money. NBER Working Paper Series, November, 1999.

EDWARDS, S. (2000) Capital Flows and the Emerging Economies. Theory, Evidence and Controversies. The University of Chicago Press, 2000

EDWARDS, S. (1999). How Effective are Capital Controlas? NBER Working Paper Series 7413. Cambridge, USA, November, 1999.

EDWARDS, S. (1998). Capital inflows into Latin America: a stop-go story. NBER Working Paper Series 6441. Cambridge, USA, Março, 1998.

FLOOD, R. P. e ROSE, A. K. (2001) Uncovered interest parity in crisis: the interest rate defense in the 1990s. IMF Working Paper, 01/207, December, 2001.

GARCIA, M. e VALPASSOS, M. V. (1998). Capital flows, capital controls and currency crisis: the case of the Brazil in the nineties. Rio de Janeiro, Texto para Discussão PUC-Rio No. 389, Novembro, 1998.

GOURINCHAS, P.; VALDES, R. e LANDERRRETCHE, O. (2001) Lending Booms. Latin America and the World. NBER Working Papers, 8249.

GRANGER, C. W. (1969). Investigating Causal Relations by Econometric Models and Cross-Spectral Methods. Econometrica, 37, 42.4-438.

HOLLAND, M. e VIEIRA, F. V. (2003) Country Risk Endogeneity, Capital Flows and Capital Controls in Brazil. Brazilian Journal of Political Economy, Vol. 23, N.1, Jan-Mar, 2003.

HAMILTON, J. (1995). Time Series Analysis. Princeton: University Press.

KAMINSKY, G. e SCHMUKLER, S. (2000). Short and long run integration: do capital controls matter? Washington, D.C. The World Bank, 2000.

KRUGMAN, P. (1979) A Model of Balance of Payments Crisis. Journal of Money, Credit and Banking, August, 1979.

LANGHAMMER, R. J. e WOBMANN, L. (2000) Foreign capital flows into emerging Markets. When do they help, when do they hurt? The kiel institute of world economics.

MACKINNON, J. (1991) Critical Values for Cointegration Tests. In: R. F. Engle e C.W.J. Granger (eds.) Long-run economic relationships. Readings in cointegration. Advanced texts in econometrics.

MONTIEL, P. e REINHART, C. (1999). Do capital controls and macroeconomic policies influence the volume and composition of capital flows? Evidence from the 1990s. NBER Working Paper Series, Março, 1997. 
PASTORE, A. C. (2000). Globalização, fluxos de capitais e regimes cambiais Reflexões sobre o Brasil. São Paulo. AC Pastore e Associados, 2000.

RAZIN, A e SADKA, E. (2002) A Brazilian Debt Crisis. NBER Working Paper Series, 9160, September, 2002.

REINHART, C. e SMITH, R. T. (2001) Temporary Controls on Capital Inflows. NBER Working Paper Series 8422, August, 2001.

STOCK, J. H. e WATSON, M. W. (2001). Vector Autoregessions. Joumal of Economic Perspectives, Symposium on Econometric Tools. Março, 2001.

\section{APÊNDICE}

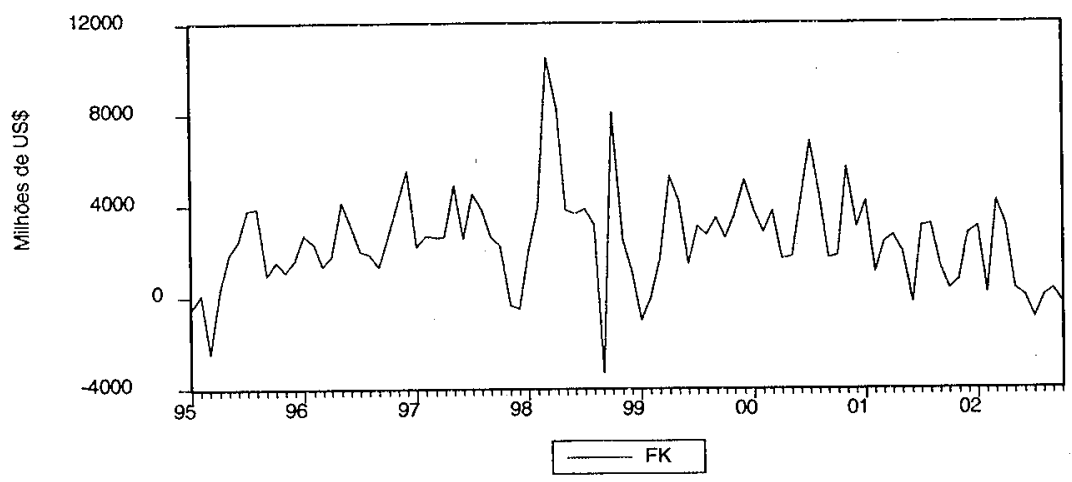

\section{Gráfico I: Fluxo de capital no Brasil (jan. I996 a out. 2000)}

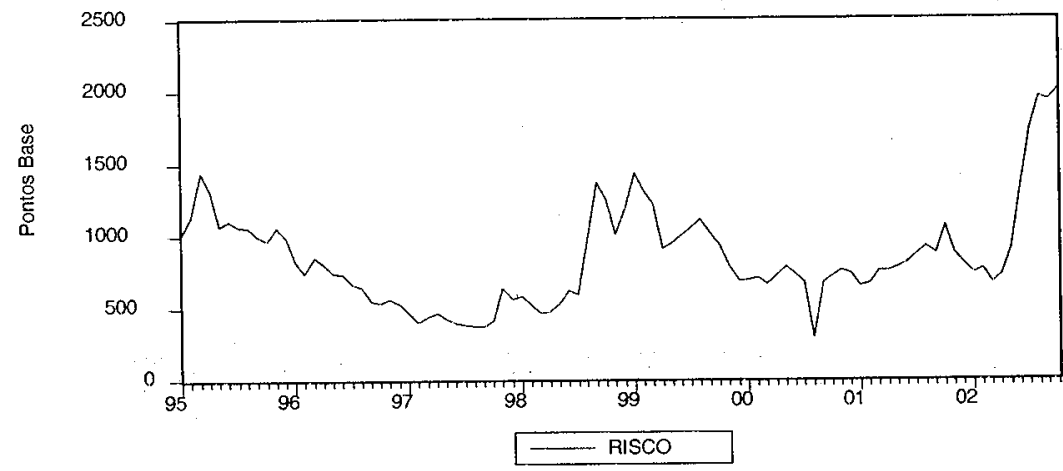

\section{Gráfico 2: Risco-Brasil (jan. 1996 a out. 2002)}




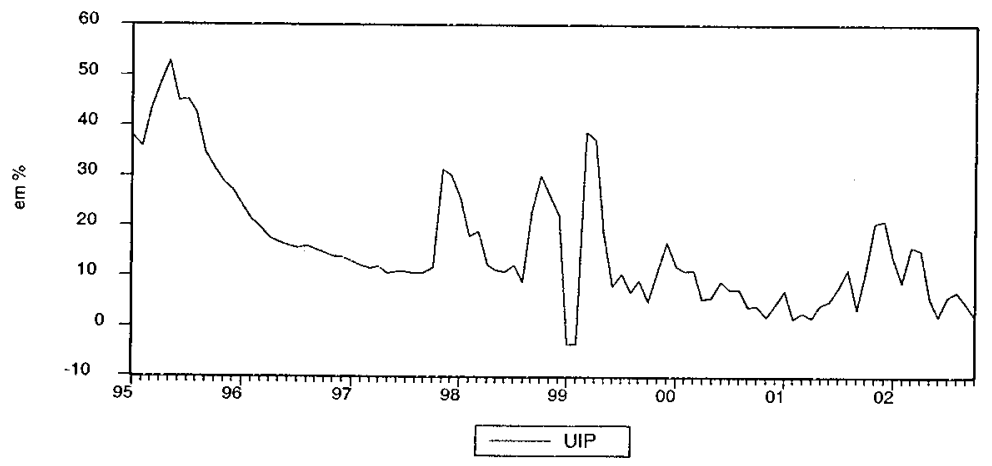

Gráfico 3: Diferencial de juros - Brasil (jan. 1996 a out. 2002)

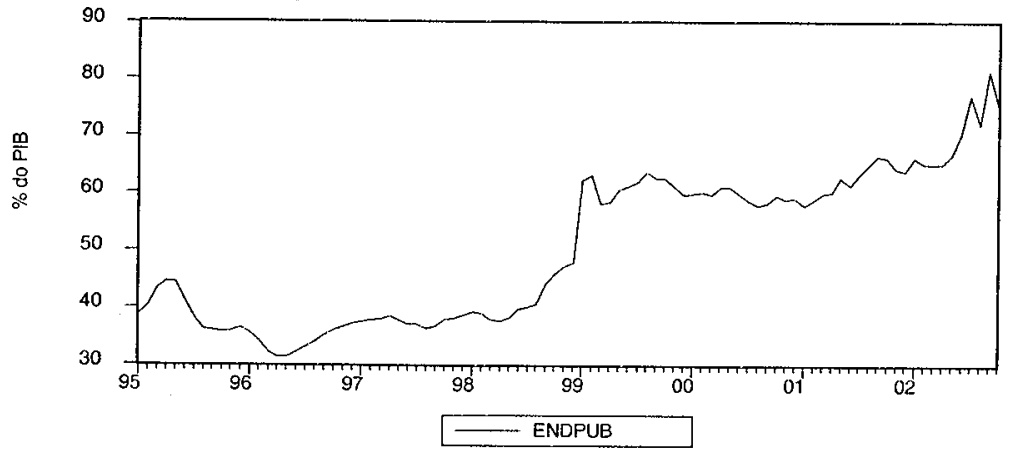

Gráfico 4: Endividamento público - Brasil (jan. 1996 a out. 2002)

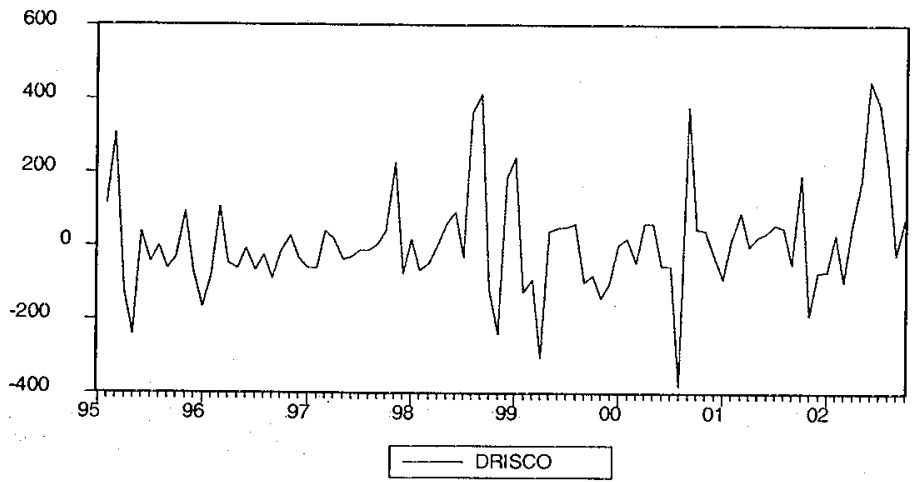

Gráfico 5: Risco Brasil em primeira diferença (jan. 1996 a out. 2002)

Endividamento público e impacto sobre fluxo de capitais, risco-país... 


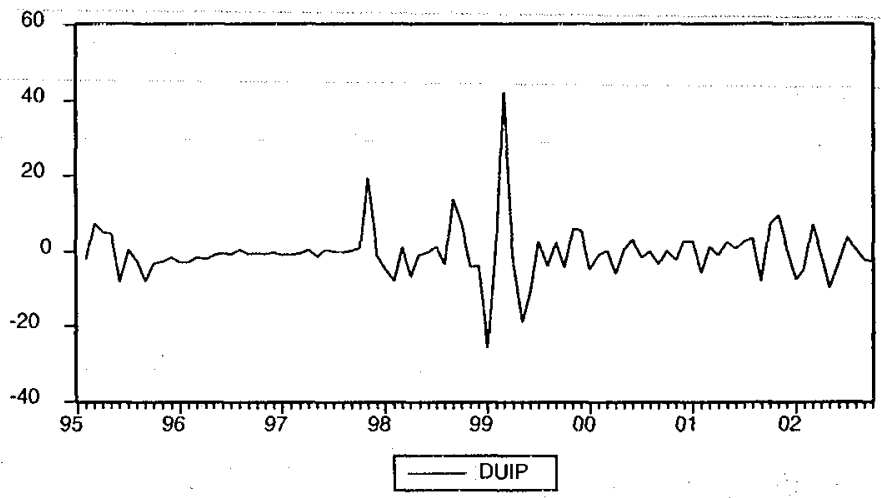

Gráfico 6: Diferencial de juros - Primeira diferença Brasil (jan. 1996 a out. 2002)

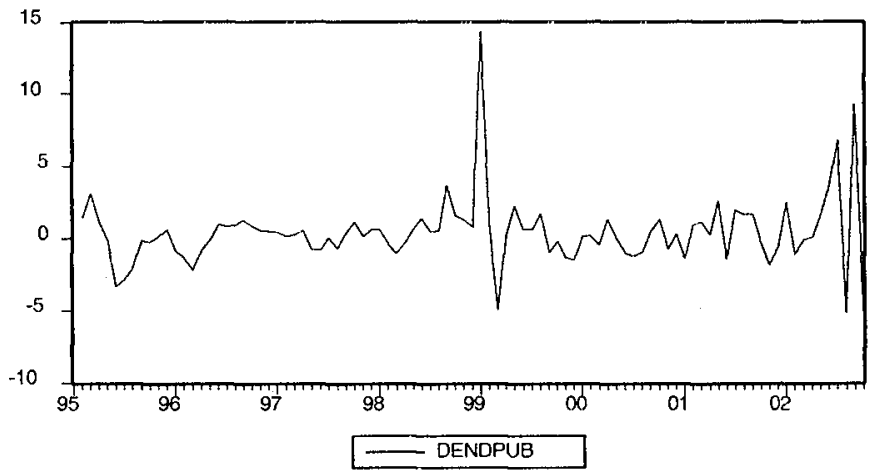

Gráfico 7: Primeira diferença do endividamento público (jan. 1996 a out. 2002) 